\title{
AQUISIÇÃO DA VARIAÇÃO: A INTERFACE ENTRE AQUISIÇÃO DA LINGUAGEM E VARIAÇÃO LINGUÍSTICA
}

\section{Aline LORANDI*}

- RESUMO: Este trabalho consiste em uma explanação sobre uma valiosa área de estudo, criada na interface entre aquisição da linguagem e sociolinguística variacionista - a aquisição da variação. A partir de importantes estudos realizados nesta área, abordamos conceitos fundamentais para o entendimento sobre a aquisição da variação e sobre a criança como membro da comunidade linguística. O objetivo deste artigo é apresentar um referencial teórico dos estudos sobre aquisição da variação, visto que este é um fenômeno ainda pouco explorado no âmbito da pesquisa linguística brasileira. Além disso, este trabalho apresenta um exercício de pesquisa variacionista, com dados de fala infantil sobre o fenômeno variável de concordância verbal (amparado pelos estudos de Scherre e Naro (1998)), para o qual foi desenvolvida uma coleta de dados nos moldes da sociolinguística variacionista, com os ajustes devidos ao trabalho com crianças, tal como evidenciado em importantes trabalhos da área, como os de Roberts $(1997,2002,2005)$.

- PALAVRAS-CHAVE: Aquisição da variação. Sociolinguística. Concordância verbal.

\section{Introdução}

Este artigo tem por objetivo discorrer sobre a interface que se cria quando aliamos os estudos variacionistas aos de aquisição da linguagem, trazendo pesquisas importantes das áreas em questão, com o intuito de reunir informações valiosas que argumentem em favor da importância do estudo dessa interface. Além disso, salientamos a importância dos esclarecimentos do que vem a ser a aquisição da variação, tomando o termo "variação" no sentido que a Teoria Laboviana o emprega, e não no sentido tradicionalmente utilizado pelos estudos de aquisição da linguagem. Para facilitar a explanação desse tipo de estudo recente e ainda pouco explorado no Brasil - um exemplo de análise será mostrado, a partir do estudo da aquisição da regra variável de concordância de número em verbos do Português Brasileiro, regra esta já averiguada, descrita e estudada na fala adulta (SCHERRE; NARO, 1998; NARO; SCHERRE, 2007). Além disso, na seção referente à aquisição da variação, alguns estudos já realizados em outros países serão brevemente descritos.

* UNIPAMPA - Universidade Federal do Pampa. Bagé - RS - Brasil. 96413170 - alinelorandi@unipampa.edu.br 
Roberts (2002) afirma que a variação da linguagem da criança é um tipo de estudo relativamente novo dentro do campo da Sociolinguística. Apesar de os estudos sobre aquisição da linguagem constituírem um ramo teórico e científico mais antigo, as atenções sempre foram direcionadas para as regularidades e para o sistema de competência da criança tradicionalmente concebidos, tendo as questões dialetais ficado à margem durante muitos anos. Além disso, os estudos variacionistas possuem características muito particulares, especialmente no que se refere à coleta e à quantidade de dados, o que não seria possível depreender dos dados tal como são usualmente coletados ${ }^{1}$ em uma pesquisa sobre aquisição da linguagem. Esses aspectos serão, posteriormente, discutidos em maiores detalhes.

Os estudos na área da variação, por sua vez, conforme Roberts (2002), têm aproximadamente 40 anos e, portanto, constituem uma ciência recente. É lógico pensar - e Roberts (2002) faz um comentário nesse sentido - que, assim como é pouco provável pensar na aquisição da linguagem sem um bom volume de pesquisas sobre a linguagem do adulto, para que se possa comparar a linguagem emergente da criança com a do adulto, seu alvo, também os estudos variacionistas, se debruçaram, inicialmente, sobre as questões dialetais do adulto, para, em um segundo momento, voltar seu olhar para a linguagem da criança, buscando incluí-la no quadro da comunidade linguística em que se insere e, portanto, dedicando atenção aos seus dados como valiosos para completar seu entendimento sobre uma determinada comunidade. Roberts (2002) ainda comenta que as razões para o trabalho em variação linguística e mudança não terem focado a fala da criança parecem razoáveis, visto que esse é um novo campo de estudos linguísticos, que foi construído sobre bases da dialetologia, uma disciplina notavelmente voltada para a fala adulta. Durante muito tempo, a criança foi vista como alguém que está adquirindo o vernáculo e não, necessariamente, como alguém que contribui para a sua manutenção e mudança.

Apesar de recentes, importantes trabalhos já foram e estão sendo desenvolvidos nessa interface que une a sociolinguística e a aquisição da linguagem enquanto ciências. O que se percebe, em um primeiro olhar sobre essa interface, é que esses estudos vêm sendo desenvolvidos por variacionistas e não, necessariamente, por estudiosos da aquisição da linguagem. Dessa forma, eles possuem a mesma estrutura - muito característica e bem arranjada - dos estudos tradicionais realizados à luz da Teoria da Variação Laboviana.

Roberts (2002) comenta que esse é um dos problemas que pode ter dificultado a pesquisa dialetal em aquisição da linguagem, já que os dados, muitas vezes, são registros de diário, com uma só criança ou estudos que reúnem, de modo geral, pouca quantidade de dados, o que inviabiliza, no seu ponto de vista, uma análise estatística. 


\section{Um breve histórico sobre os estudos da variação linguística da criança}

Roberts e Labov (1995) afirmam que a aquisição da variação por aprendizes de primeira língua é uma área que foi negligenciada por um longo tempo na história da sociolinguística. Roberts (2002), na obra Handbook of language and change, em seu capítulo dedicado à variação linguística da criança, faz um excelente apanhado dos estudos que foram realizados sob essa perspectiva variacionista, voltada para dados da linguagem da criança. Os trabalhos foram "diminuindo" a idade gradativamente. Labov (1964) observou que, embora muitos traços dialetais sejam aprendidos na infância, é durante a adolescência que a variação socialmente significativa é demonstrada. Todavia, a partir de resultados encontrados em adolescentes e adultos, pareceu útil olhar para o dialeto das crianças, visando a responder a algumas questões de variação linguística e mudança.

De acordo com Roberts (2002), um dos primeiros trabalhos a incluir dados de crianças foi o de Fischer (1958), que encontrou variação social em crianças entre 3 e 10 anos e variação estilística em meninos com 10 anos. Todavia, esse autor não separou as crianças por idades, etapa fundamental em um trabalho sobre aquisição da linguagem, já que muitos são os avanços e as mudanças, nessa etapa do desenvolvimento, de um ano para o outro e, até mesmo, de um mês para o outro, dependendo do aspecto sob análise. Roberts (2002) comenta que isso tornou impossível determinar se as crianças mais novas participavam do resultado total ou não, que mostrava o padrão documentado. Nesse mesmo sentido, a autora referencia o trabalho de Purcell (1984), que registrou variação social e estilística operando em muitas variáveis produzidas por falantes de havaiano e de inglês americano "geral", com idades entre 5 e 12 anos. Assim como Fischer, Purcell não dividiu as crianças por idades, e a diferença entre crianças de 5 e de 12 anos é consideravelmente grande, dado o foco da pesquisa. Dessa forma, não se pode perceber, devido a essa questão metodológica, em que medida as crianças mais jovens participam dos resultados.

Um dos primeiros estudos a olhar para a variação em crianças pré-escolares, conforme o levantamento de Roberts (2002), é o de Kovac e Adamson (1981), que examinou um fenômeno já muito bem documentado no inglês afro-americano, que é o apagamento de "be" finito. O estudo focou o inglês afro-americano e o euro-americano na fala de crianças de $3 ; 5^{2}$ e 7 anos. O resultado, muito interessante, revelou que, no inglês euro-americano, o apagamento de "be" pareceu ser desenvolvimental, enquanto, para as crianças falantes do inglês afro-americano, os resultados variaram de acordo com a classe sócio-econômica.

3 anos; 5 meses. 
Além disso, os autores observaram que as restrições sobre o apagamento foram mais difíceis de adquirir do que a regra em si. As restrições sobre a contração, fenômeno diretamente ligado ao apagamento, como mostra o estudo de Labov (1969), foram adquiridas por ambos os grupos aos 3 anos de idade, mas as restrições sobre o apagamento típico do adulto ainda não haviam sido completamente adquiridas aos 7 anos.

Guy e Boyd (1990) examinaram outro fenômeno já bem estudado e descrito no inglês, ou seja, o apagamento de ( $t$, d) em verbos "semifracos" ou "ambíguos" do tempo passado, com falantes entre 4 e 65 anos. Os autores concluíram que a aquisição do apagamento de $(t, d)$ em verbos semifracos é um processo potencialmente longo com os falantes mais jovens, não produzindo os segmentos oclusivos num todo, o que os levou a acreditar que não estavam presentes nas representações subjacentes dessas formas. Roberts (1997) apresenta um resultado diferente para esse mesmo fenômeno, com crianças entre 3 e 4 anos, que será abordado posteriormente. Um estudo de Labov (1989), sobre a variação estilística e linguística dessa mesma variável, e da aplicação de (ing), em uma amostra pequena de crianças e de seus pais da área King of Prussia, da Filadélfia, mostrou que um menino de 7 anos replicou os padrões estilísticos e linguísticos de seus pais para o apagamento de $(t, d)$, com exceção do tratamento dado aos verbos semifracos, os quais foram analisados como palavras monomorfêmicas, apresentando o mesmo padrão de apagamento de (t, d). Essa mesma criança também lidou com as restrições linguísticas e estilísticas da alternância de (ing), enquanto outra, de 6 anos, lidou somente com a variação estilística, e outra, de 4 anos, não mostrou qualquer sinal de estar adquirindo as restrições da alternância dessa variável.

Antes de seguir com a explanação sobre a relevância dessa área de estudos, mostrando suas peculiaridades e exemplos práticos de aplicação desses conhecimentos com outras variáveis, julgamos importante tratar, de forma muito breve, das características de um estudo tipicamente variacionista, as quais permeiam todos os estudos que serão aqui trazidos.

\section{Estudos variacionistas e sua metodologia}

Os estudos realizados sob o prisma da Teoria da Variação são um exemplo de uma metodologia bem definida, que atende a requisitos de descrição e explicação, fundamentais à pesquisa científica séria, "[...] à medida que minimiza princípios explicativos e dá conta dos dados de forma mais geral." (GUY; ZILLES, 2007, p.43).

Como nos ensina Tarallo (2002), a pesquisa variacionista visa a desfazer o equívoco de que a variação linguística é caótica e desordenada, buscando, 
por meio da descrição cuidadosa dos dados, coletados a partir de critérios muito bem definidos, da análise estatística e da posterior análise linguística depreendida dos dados, revelar o padrão que subjaz a essa variação, o qual faz parte do sistema linguístico de cada falante e da comunidade linguística à qual pertence. De acordo com Guy e Zilles (2007, p.20), uma análise quantitativa compreende, resumidamente, três etapas: "i) coleta de dados; ii) redução e apresentação dos dados e iii) interpretação e explicação dos dados". De forma abreviada, podemos definir as etapas da pesquisa sociolinguística tal como segue. O primeiro passo é determinar a variável dependente que será estudada. A partir da escolha da variável, é fundamental, por meio de um conhecimento da comunidade de fala ou da postulação de possibilidades lógicas de ocorrência, efetuar o levantamento das variantes em questão. Feito isso, é interessante fazer uma pesquisa sobre a história dessa variável na língua em estudo e sobre outros estudos já realizados sobre o assunto (library research, como define Feagin (2002)), a fim de verificar as tendências à mudança ou à variação estável.

Um segundo passo crucial é realizar um estudo sobre a comunidade em que se fará a pesquisa (estudo etnográfico, etapa também indicada por Feagin (2002)). Desse estudo, emergirão as variáveis sociais independentes e poderemos entender o modo de vida das pessoas que fazem parte da comunidade, bem como perceber que características sociais, econômicas e culturais trazem os informantes. Em seguida, conhecimentos fonéticos e fonológicos são exigidos para que possamos determinar as variáveis linguísticas independentes.

Realizados esses estudos prévios, pensamos os critérios para a coleta de dados, que devem atender às variáveis independentes em questão, no que diz respeito às características dos informantes e à obtenção de dados relevantes para a análise. A escolha de equipamento adequado, nessa etapa da pesquisa, também é importante. O momento de seleção de informantes e de coleta de dados é um dos momentos cruciais de uma pesquisa variacionista. Após as coletas e o levantamento dos dados e de seus respectivos contextos de ocorrência, procedemos à análise estatística, que insere esse tipo de pesquisa em uma área conhecida como "sociolinguística quantitativa", tal como lembra Tarallo (2002). Esse tipo de pesquisa exige grande e representativa quantidade de dados, e esse é um aspecto que deve ser observado durante a obtenção de dados na entrevista com os informantes. Da análise estatística provêm os dados que, aliados aos fundamentos teóricos, resultarão na análise linguística do fenômeno em estudo, em que procuramos situar essas informações no sistema linguístico do falante, a partir da formulação de uma regra variável, e, também, mostrar a relevância da consideração de aspectos sócio-econômico-culturais no estudo da linguagem humana. 
É importante observarmos que essa metodologia guia todos os trabalhos trazidos neste artigo que unem aquisição de linguagem e variação, o que demonstra a robustez desse modelo teórico e a qualidade dos pesquisadores, cujos trabalhos, pioneiros ou mais recentes, revelam o que tem sido desenvolvido nessa área de estudos.

\section{Por que estudar a variação linguística das crianças ou a aquisição da variação?}

Antes de respondermos a essa questão, cabe explicar a diferença entre a variação linguística das crianças e a aquisição da variação, já que poderiam parecer a mesma área de concentração. A variação linguística dentro de uma comunidade pode ser observada em falantes de diferentes idades e, inclusive, a variável idade é frequente nos estudos. Todavia, estudar a variação em adultos, em adolescentes e em crianças pode trazer resultados diferentes, mas todos esses estudos versarão sobre a comunidade de fala, já que adultos, adolescentes e crianças fazem parte da comunidade e contribuem para a manutenção ou para a mudança de determinadas variantes. A aquisição da variação diz respeito ao estudo de como e quando determinada regra variável é adquirida pela criança, quando passa a fazer parte do seu sistema linguístico. O estudo da aquisição da variação ${ }^{3}$ leva à importância de se considerar a criança como membro da comunidade de fala.

Durante muito tempo, os estudos variacionistas dedicaram-se a investigar apenas a fala do adulto. As razões são de diferentes ordens. Primeiramente, é importante considerar que, na tradição de qualquer estudo linguístico, todo fenômeno deve ser bem descrito e estudado a partir da fala adulta porque esta revela o sistema da língua considerado "pronto". Uma vez descrito o fenômeno ou a gramática adulta, é possível voltar-se para a fala da criança, de modo a buscar evidências da aquisição desse fenômeno ou dessa gramática, já que existe um padrão em que se basear. É como pensarmos em descrever como uma criança aprende a caminhar sem sabermos como funciona o processo de caminhar: não saberemos o que esperar da criança ou, até mesmo, o que analisar. O mesmo pode ser pensado acerca da variação linguística. Somente após um mapeamento completo do comportamento de determinada variável e de suas variantes, do estabelecimento (ou não) de uma regra variável, é que podemos buscar uma investigação sobre em que momento essa regra passa a ser adquirida pela criança e como funciona essa aquisição.

Existe, ainda, outro tipo de variação, que ocorre durante o processo de aquisição da linguagem, e que é própria do processo (desenvolvimental), mas que não significa aquisição de regra variável. A variação decorrente das etapas de desenvolvimento da linguagem constitui um dos problemas para o estudo da aquisição da variação, pois é difícil, em alguns momentos, determinar o que é uma variação dialetal e o que é uma variação na linguagem da criança (ROBERTS, 2002). 
Outra razão consiste na hipótese de que o vernáculo é considerado estável apenas na idade adulta (LABOV, 1994). Estudos como o de Bailey (2004) mostram que adolescentes tendem a mostrar instabilidade do vernáculo e que apenas ao atingirem o início da idade adulta passam a revelar alguma estabilidade. Recentemente, os estudos sociolinguísticos começaram a entender a criança como parte da comunidade linguística. Além disso, a fala infantil pode revelar importantes informações para o estudo da variação, já que é atestado, como no estudo de línguas crioulas, que as crianças revelam, por meio da aquisição da linguagem, quando um crioulo passa a ser internalizado como língua da comunidade. Também o estado de mudança de uma variável pode encontrar importantes pistas e indícios no processo de aquisição da linguagem e, então, encontramos mais uma justificativa para reconhecer a validade desse tipo de investigação. Neste artigo, mostraremos, brevemente, como se comporta a regra de concordância variável de plural em elementos verbais do português brasileiro, na fala adulta (SCHERRE; NARO, 1998) e na fala da criança (pesquisa desenvolvida por esta autora).

Toda pesquisa possui questões norteadoras. Algumas das possíveis questões que norteiam os estudos sobre aquisição da variação, tal como formuladas por Smith, Durham e Fortune (2007), são:

- O input do cuidador da criança difere das normas da comunidade em geral em todas as variáveis linguísticas?

- As formas variáveis estão evidentes desde o início do processo de aquisição, ou seja, são aprendidas ao mesmo tempo em que formas categóricas são aprendidas?

- Que efeitos o input do cuidador tem sobre as formas produzidas durante seu processo de aquisição, não somente em termos de frequência de uso, mas também em termos de restrições internas e externas na variabilidade?

- A competência sociolinguística é adquirida ao mesmo tempo em que a competência gramatical?

- Todas as variáveis linguísticas são adquiridas ao mesmo tempo e do mesmo jeito?

Roberts (1997), em seu estudo sobre o apagamento de (t, d) em formas verbais do tempo passado em inglês, formula as seguintes questões, que podem ser aplicadas a outros estudos sobre aquisição de regra variável:

- As crianças adquiriram a regra variável de apagamento de (t, d) e suas restrições internas e externas?

- Essas regras podem ser construídas como um reflexo de processos naturais, universais, que afetam a aquisição da linguagem?

- As crianças estão adquirindo essas regras ou simplesmente copiando as formas de superfície de seus pais ou de outros modelos linguísticos? 
Essas questões nos levam a entender a importância, por exemplo, da análise do input linguístico da criança, o que não é necessariamente importante para toda pesquisa em aquisição da linguagem. O papel do input é importante não só por representar a fala da comunidade em que a criança está inserida, mas também porque é preciso: verificar em que medida a criança adquire e aplica regras por si e até que ponto ela imita; averiguar a relevância de medidas de frequência de uso e de adequação aos contextos sociais; examinar questões referentes a estilo e a gênero sexual, a partir da possível interferência da fala da mãe (sexo feminino) na escolha de variantes de filhas e de filhos.

A partir dessas questões e do que entendemos por aquisição da linguagem, concordamos com Roberts (1997), quando diz que um modelo completo de aquisição demanda a inclusão de todas as formas da linguagem, tanto as variáveis quanto as categóricas em sua natureza, afinal, como afirmam Weinreich, Labov e Herzog (1968), a visão da linguagem como um "objeto homogêneo" é irreal, e muitos estudos já documentaram a variabilidade inerente da língua, a qual, segundo os autores, não é apenas uma questão de multidialetalismo ou "mero" desempenho, mas parte da competência linguística. Além disso, como Andersen (1990) nota, as crianças devem aprender o dialeto ou o conjunto de dialetos que marcará certos aspectos da sua identidade social, incluindo sua região de origem, assim como sua classe social, seu grupo étnico, sua idade e gênero. Elas devem, ainda, aprender a variação estilística que permitirá a elas mudarem de um grupo social para outro ou de um tópico conversacional para outro. O fato de a variação fazer parte da linguagem da criança inclui esse tipo de estudo no âmbito dos estudos sobre aquisição. Se esse tipo de estudo não for realizado ou se essa realidade for negligenciada, estaremos claramente deixando de lado a oportunidade de conhecer o todo do processo de aquisição da linguagem pela criança.

Outra justificativa para o estudo da aquisição da variação é formulada por Foulkes e Docherty (2006), que consideram uma forma produtiva de examinar a representação de material sociofonético investigar como tal informação é aprendida durante o curso da aquisição da linguagem.

Após essas considerações acerca de por que estudar a variação na fala da criança e a aquisição da variação, concentremo-nos mais detalhadamente sobre o input da criança pequena, em fase de aquisição: a fala dirigida à criança4 ${ }^{4}$.

\section{O input variável: evidências da fala dirigida à criança}

Os estudos sobre aquisição da variação não tomam apenas a fala da criança como fonte de dados, mas envolvem, também, a fala da mãe, que, em geral,

No inglês, Child Directed Speech (CDS). 
é a principal cuidadora da criança nessa fase da vida e, portanto, a principal fornecedora de input linguístico. Labov (1989) notou que o input linguístico das crianças é variável, como demonstrado por várias pesquisas na variação adulta, o que significa que o output da criança também o seria. Como afirma Roberts (2002), com a evidência existente que dá suporte à hipótese de que as crianças adquirem padrões variáveis antes de formas categóricas, ou paralelamente a elas, os pesquisadores começaram a dedicar maior atenção ao input da criança. Folkes e Docherty (2006) consideram que o conhecimento linguístico da criança é baseado, em parte, na sua análise do ambiente linguístico, ou seja, o input. O input, por sua vez, é repleto de variação. Os autores afirmam que as crianças recebem input de diferentes pessoas e ouvem sons e palavras de diferentes vozes. Dessa forma, nenhuma criança experimentaria precisamente o mesmo input. A variabilidade fonética no input, entretanto, conforme consideram esses autores, não é puramente idiossincrática; alguma variabilidade provê informação específica de língua, que deve ser adquirida como parte do conhecimento gramatical, o que incluiria alternâncias morfológicas e alofones contextuais, por exemplo. Além disso, eles comentam que o input provavelmente contenha variação fonética socialmente determinada. A fala em situações de instrução ou disciplina pode diferir em sua composição linguística daquela encontrada em situações mais informais de brincadeira e intimidade, como revelam os estudos de Roberts (1997) e de Smith, Durham e Fortune (2007) e, de acordo com esse último, também variam em contextos sintáticos diferentes, tais como em frases interrogativas ou declarativas.

Os estudos acerca da fala dirigida à criança - o manhês ${ }^{5}$ - revelam que esta difere, em alguns aspectos, da fala madura. Os estudos sobre a aquisição da variação confirmam essa afirmação. Pesquisas como as de Snow, de Newport e deWexler e Culicover discutem sobre a hipótese de o manhês ser uma espécie de instrução dada à criança, que facilitaria a aquisição. Enquanto Snow (1972) defende essa hipótese, os demais questionam essa forma "facilitadora", mostrando que a fala dirigida à criança não é necessariamente mais fácil ou simples (NEWPORT, 1977) e comentando que aqueles que afirmam ser essa fala mais simples e mais bem "afinada" com as necessidades da criança dificilmente explicam por que essa simplicidade seria útil para a aquisição da língua pela criança (WEXLER; CULICOVER, 1980).

De forma geral, os estudos concordam em alguns pontos:

- A fala com crianças é mais simples do que com adultos;

- As sentenças são mais curtas e foneticamente mais coerentes;

- As orações são sintaticamente mais simples;

Em inglês, motherese. 
- Há um uso maior de termos dêiticos;

- São utilizadas expansões e repetições;

- A fala é mais lenta do que com outros adultos;

- O timbre de voz é mais alto;

- O padrão de entonação é exagerado;

- Palavras comuns podem adaptar-se à estrutura CVCV.

Foulkes e Docherty (2006) acrescentam que os padrões fonéticos no input também podem variar, mais notadamente na entonação. Eles afirmam que é comum utilizar, com adultos, uma média mais alta da frequência fundamental e, com a criança, uma média de timbre mais estendida. Além disso, os autores afirmam que há evidência de que o input pode variar de acordo com o sexo e a idade da criança. De modo geral, a variação na fala da criança pode refletir diferentes oportunidades de aprendizagem providas por diferentes padrões de input. Além dessas características, alguns estudos, tais como os relatados por Roberts (2002), mostram que as mães utilizam mais formas-padrão com as crianças do que com adultos. A autora, assim como Snow (1972), acredita que as mães parecem assumir seriamente seu papel como "professoras da língua", utilizando a fala dirigida à criança para ajudá-la nesse processo.

\section{A aquisição da variação}

Chambers (2003) afirma que, quando as crianças adquirem a sua língua materna, elas evidentemente adquirem as variantes locais e as normas de seu uso também. Estudos mostram que as crianças não só aprendem que as formas variam, como também "sabem" quando é apropriado usar uma ou outra, dependendo do contexto social de uso. A questão, tal como formulada por Smith, Durham e Fortune (2007), é como elas adquirem tal conhecimento. As autoras citam Labov (2001), que afirma que a variação linguística é transmitida para a criança como uma diferenciação estilística na dimensão formal/informal, sendo que as variantes formais são associadas pela criança à instrução e à punição, enquanto a fala informal é associada à intimidade e à diversão. Smith, Durham e Fortune (2007) concordam com essas afirmações, mas acreditam que a situação seja um pouco mais complexa, já que nem todas as variáveis são adquiridas ao mesmo tempo e do mesmo modo, dependendo do nível linguístico do traço dialetal, da complexidade do condicionamento e da idade da criança, como explica Kerswill (1996).

As análises da fala dirigida à criança não fazem menção aos padrões sistemáticos de variação, como observam Smith, Durham e Fortune (2007). Foulkes, Docherty e Watt (2005) avaliam que isso pode ser um resultado do fato de que as variedades-padrão da língua é que têm sido o foco de investigação. 
Entretanto, estudos como o de Roberts (2005) mostram que a variação não é um subproduto do processo de aprendizagem, mas uma parte integral da aquisição em si. A variação de fala do cuidador e da criança é condicionada por restrições sociais e linguísticas altamente estruturadas.

A pesquisa em aquisição da linguagem abrange diferentes idades, dependendo do foco de análise. Uma pesquisa fonológica, por exemplo, pode requerer crianças em fase bem inicial, antes, inclusive, de completarem o primeiro ano de vida, ou crianças mais velhas, caso estejamos investigando aquisição de segmentos mais complexos. Uma pesquisa que visa à aquisição de aspectos sintáticos ou morfológicos vai necessitar de crianças um pouco mais velhas, em geral, por volta dos dois anos, pois é só a partir dessa idade que as primeiras combinações de palavras com alguma estrutura sintática começam a surgir na fala e que as estruturas internas à palavra são percebidas pela criança. As pesquisas em aquisição da variação têm se concentrado, em geral, em crianças entre 3 e 4 anos (ROBERTS, 1997; ROBERTS; LABOV, 1995), já que esse é considerado "[...] um período crítico para a aquisição de normas dialetais da comunidade de fala." (ROBERTS; LABOV, 1995, p.110). Há pesquisas com crianças mais novas, como a de Foulkes, Docherty e Watt (1999), que abordou crianças de 2 a 4 anos em seu estudo sobre a variação glotal de /t/ em Newcastle, e a de Smith, Durham e Fortune (2007), em que as crianças estão na faixa dos 2;6 aos 4;0.

A coleta com as crianças é um pouco diferente da coleta com adultos, visto que são necessárias mais horas de gravação para obtermos uma boa quantidade de dados para a análise estatística e que necessitamos adaptar os métodos de entrevista. Para obtermos o efeito de entrevista, que é realizada com adultos, a sessão com a criança incluirá brincadeira livre, com uma variedade de brinquedos e de atividades estruturadas, visando à obtenção de dados. Para outros efeitos, podemos realizar brincadeiras com telefone e com "leitura" de livros, com propostas feitas pelo pesquisador, tais como "Me conta o que está acontecendo nessa história". Roberts (1997) comenta que de seis a treze sessões por criança são necessárias para igualar a quantidade de dados que se consegue, normalmente, em uma única sessão de entrevista sociolinguística com o adulto. Além das coletas com as crianças, o pesquisador coleta dados do cuidador, em geral, a mãe, para analisar efeitos do input sobre as variantes e para conseguir dados sobre o background da criança. Essa coleta pode ser realizada pessoalmente ou por telefone.

A coleta realizada com a criança tem, ainda, outro tipo de aspecto a ser observado, já que, conforme apontado por Roberts (2002), têm de se coletadas amostras de fala eficientemente, a fim de minimizar o impacto da maturação durante o período de obtenção de dados em si. 
Realizadas essas observações acerca dos estudos sobre aquisição da variação, procederemos, breve, sucinta e esquematicamente, à apresentação de alguns trabalhos, visando ilustrar os resultados a que pode chegar esse tipo de estudos.

Quadro 1 - Apresentação de estudos importantes da aquisição da variação.

\begin{tabular}{|c|c|c|c|c|c|}
\hline $\begin{array}{l}\text { Autor(es) } \\
\text { (Ano) }\end{array}$ & \multicolumn{3}{|c|}{ Variável/Variantes } & $\begin{array}{l}\text { Informantes/ } \\
\text { Idades }\end{array}$ & População/Local \\
\hline $\begin{array}{l}\text { Roberts e } \\
\text { Labov (1995) }\end{array}$ & \multicolumn{3}{|c|}{$\begin{array}{l}\text { short a } \\
\text { - vogal 'a' tensa (mad, bad, } \\
\text { entre outras) } \\
\text { - vogal 'a' lax (aspirin, sad, } \\
\text { entre outras) }\end{array}$} & $\begin{array}{l}17 \text { crianças (11 } \\
\text { meninas), } 3: 2 \text { a } \\
4: 11\end{array}$ & $\begin{array}{l}\text { Área de working-class } \\
\text { a lower middle-class do } \\
\text { sul da Filadélfia }\end{array}$ \\
\hline \multicolumn{6}{|c|}{$\begin{array}{l}\text { - A variável em questão envolveu e continua envolvendo um processo de mudança. } \\
\text { - A área em estudo foi considerada ideal por ter poucos imigrantes, mais } \\
\text { homogeneidade e menos correção estilística. É uma região de vizinhança branca } \\
\text { e muitos residentes vêm de um background italiano. Familiares moram perto } \\
\text { uns dos outros. } \\
\text { - Foram } 146 \text { horas de gravação. } \\
\text { - Oito pais foram entrevistados em suas casas. Os outros foram contatados por } \\
\text { telefone. } \\
\text { - Os resultados mostraram que as crianças estavam acessando as normas da } \\
\text { comunidade de fala e participando dessa mudança em progresso, pois, apesar } \\
\text { de ser uma variável de grande complexidade, as crianças demonstraram uso } \\
\text { adequado das variáveis, de acordo com seus contextos linguísticos e também } \\
\text { reforçaram a mudança referente à difusão lexical, evidenciando um uso maior } \\
\text { de tensing do que os adultos em alguns ambientes em mudança (tensing diante } \\
\text { de nasal intervocálica, como em planet). Esses resultados mostram que mesmo } \\
\text { membros bem jovens da comunidade de fala estão participando ativamente da } \\
\text { mudança de som em andamento. }\end{array}$} \\
\hline \multicolumn{2}{|c|}{ Autor(es) (Ano) } & Variável/Variantes & \multicolumn{2}{|c|}{ | Informantes/Idades } & População/Local \\
\hline \multicolumn{2}{|l|}{ Roberts (1997) } & $\begin{array}{l}\text { Apagamento de } \\
(\mathrm{t}, \mathrm{d}) \text { em clusters } \\
\text { de final de palavra }\end{array}$ & \multicolumn{2}{|c|}{$\begin{array}{l}16 \text { crianças (10 meni- } \\
\text { nas e } 6 \text { meninos), 3:2 } \\
\text { a } 4: 11\end{array}$} & $\begin{array}{l}\text { Área de working-class } \\
\text { a lower middlet-class } \\
\text { do sul da Filadélfia }\end{array}$ \\
\hline
\end{tabular}


- A pesquisa visava a responder à questão de como e quando essa regra variável é adquirida e como sua aquisição se relaciona com a aprendizagem da regra categórica de formação do tempo passado.

- Oito mães foram entrevistadas em suas casas. As demais foram contatadas por telefone.

- Pseudônimos foram criados para preservar a privacidade dos informantes.

- Foram levantadas restrições gramaticais (palavras monomorfêmicas com t, d no final, tais como mist ou nest; verbos semifracos, tais como slept ou left; formas fracas de tempo passado, tais como as terminadas com sufixo -ed, como em missed ou laughed) e restrições fonológicas (contexto seguinte = favorecedor quando t/d são seguidos por uma obstruinte; menos favorecedor quando t/d são seguidos por uma líquida; menos favorecedor quando seguidos por um glide, uma vogal e, menos ainda, quando seguidos por uma pausa).

- O resultado da análise revelou uma relação estreita entre os padrões das crianças e os dos adultos, documentados por Guy (1980). As crianças demonstraram ter adquirido restrições gramaticais e fonológicas que regem o apagamento de (t, d), tal como o adulto.

- Os dados com contexto seguinte marcado por pausa indicaram que é um dialeto que está sendo adquirido e não um processo universal que está sendo aplicado, já que esse contexto é menos favorecedor nessa região e não em outras.

- As crianças mostraram um padrão semelhante ao do adulto, tendendo mais ao apagamento em palavras monomorfêmicas do que em verbos fracos de tempo passado, o que indica que elas adquiriram restrições gramaticais referentes ao apagamento, já que (t, d), nesses verbos regulares, constituem a marca da flexão e, portanto, são menos propensos ao apagamento.

- Com um número maior de dados, esse estudo apresentou um resultado diferente do de Guy e Boyd (1990), que consideraram o apagamento de (t, d) em verbos semifracos categórico e que, portanto, os /t/s e /d/s não existiam para aquelas crianças. O resultado de Roberts mostra que os verbos semifracos apresentam um padrão semelhante ao das palavras monomorfêmicas, ou seja, o apagamento não é categórico, e os segmentos finais desses verbos estão presentes para essas crianças, mas são analisados como existindo dentro de um único morfema, e não como marcadores produtivos de tempo passado. Os adultos, por sua vez, mostram uma análise de verbos semifracos mais semelhante à de verbos fracos de tempo passado. Esse desvio do padrão adulto sugere que as crianças estão formulando análises de seu próprio padrão como parte de um processo de aprendizagem de regra, e não se conformando com tendências universais. Além disso, esse resultado mostra que crianças de 3 anos estão no processo de aquisição de formas gramaticais mais complexas e que elas aprendem essa variação ao mesmo tempo em que as formas gramaticais. 


\begin{tabular}{|c|c|c|c|}
\hline Autor(es) (Ano) & Variável/Variantes & Informantes/Idades & População/Local \\
\hline $\begin{array}{l}\text { Smith, Durham e } \\
\text { Fortune (2007) }\end{array}$ & $\begin{array}{l}\text { 1) Variável hoose } \\
\text { - ditongo / } \Lambda \text { u/ } \\
\text { - monotongo /u:/ } \\
\text { 2) marcação de plural } \\
\text { - s emcontextos de } 3^{a} \\
\text { pessoa do plural- are, } \\
\text { nos mesmos contextos }\end{array}$ & 24 díades; $2: 6$ a 4:0 & $\begin{array}{l}\text { Buckie, uma peque- } \\
\text { na cidade de pes- } \\
\text { cadores, situada à } \\
\text { costa nordeste da } \\
\text { Escócia }\end{array}$ \\
\hline
\end{tabular}

Considerações importantes, com relação à variável hoose:

- Dez horas de gravação de dados criança/cuidador, das quais 5 foram totalmente transcritas.

- Havia, também, além do corpus com as díades, um corpus com falas adulto/adulto, com aproximadamente 300.000 palavras.

- O corpus criança/adulto abarcava situações formais e informais; o corpus adulto/ adulto, apenas contexto de uso informal.

- Os estudos sincrônicos sobre essa variável dedicam atenção especial para estratificação de classe, mudança de estilo, idade e condicionamento lexical.

- A forma local é a monotongada e é estigmatizada por alguns grupos de falantes.

- O estudo analisou os dados por grupo e individualmente.

- Os resultados mostram que:

- quando os cuidadores usam altos índices da variante local, as crianças também o fazem;

- a variante local é mais utilizada em contextos informais, tais como brincadeira e rotina, tanto pelos cuidadores quanto pelas crianças, apresentando uma quantidade de ocorrência bem próxima nos dois grupos. Em situações formais, de ensino e disciplina, esse índice decresce consideravelmente;

- a análise individual mostrou que, quando o cuidador apresentava índices de produção diferentes dos demais, a criança também o fazia, evidenciando o papel importante do input;

- as variáveis sofrem influência de itens lexicais. Em termos de itens lexicais, se uma palavra favorecia a variante local para o cuidador, favorecia, também, para a criança;

- o input do cuidador difere das normas da comunidade em geral. Há muito mais uso da variante padrão na fala do cuidador;

- as crianças pareceram começar com apenas uma das formas: a forma padrão; 
- os cuidadores utilizaram baixos índices da variante local com as crianças mais jovens;

- houve uma correlação significativa entre cuidadores e crianças a respeito da frequência de uso;

- uma vez que as crianças haviam começado a usar as duas formas, elas rapidamente adquiriam as restrições estilísticas externas do seu uso. As crianças também mostraram evidência de aquisição de restrições internas, já que lidaram com itens lexicais e com diferenciação de acordo com a função, como no caso da palavra now.

Considerações importantes, com relação à variável de plural:

- Assim como com a variável hoose, as crianças iniciam o processo de aquisição com a forma padrão.

- As crianças não mostraram diferenças no uso com referência a estilo.

- O uso de -s na $3^{\mathrm{a}}$ pessoa do plural mostrou altos índices em todos os dialetos estudados e, de fato, o uso de -s nesses contextos é registrado em todas as classes sociais.

- Houve um uso quase categórico de -s em contextos existenciais.

- O uso de -s com os demonstrativos this/that, em contextos de plural, foi considerado categórico, com 100\% de produção para a comunidade em geral, para os cuidadores e para as crianças. É interessante observar, também, que this e that são usados no plural. Apenas 14\% da amostra utilizou as formas-padrão those e these em contextos de plural.

- Os contextos sintáticos de interrogação favoreceram mais a utilização da variável -s do que os contextos declarativos.

- O contexto com verbo to be favoreceu mais a variável -s do que outros verbos.

- O input mostrou um papel importante, mas somente em termos de restrições internas.

- O estudo mostrou a interdependência da comunidade, do cuidador e da criança na aquisição de uma gramática que tem variação na sua fonte.

- Em suma, a variável hoose mostrou que a variável local possui restrições internas e externas e que as crianças adquirem as duas. A variável de marcação de plural apresentou, para o uso de -s, apenas restrições internas.

Fonte: Elaboração própria. 
Os estudos realizados no âmbito da interface entre aquisição da linguagem e variação linguística são recentes, mas revelam um campo produtivo de pesquisas, com robustez de análise e objetivos bem definidos, focados em mostrar que as crianças, de fato, adquirem alguns padrões variáveis complexos bem cedo e podem começar o uso social da variação ao mesmo tempo. Para o futuro, de acordo com Roberts (2002), os resultados apresentados podem ser replicados com variáveis adicionais, dialetos adicionais, em outras comunidades de fala. A autora considera que poderia ser um bom objetivo para pesquisas futuras adicionar aos estudos já existentes uma exploração do significado social emergente da variação da criança dentro das famílias e grupos de pares interacionais.

\section{Aquisição de regra variável: o caso da variação na concordância verbal}

Para que possamos verificar como pode ser realizado um estudo sobre a aquisição de regra variável, decidimos observar um fenômeno de variação em dados de crianças falantes de português brasileiro (PB). Para tanto, optamos por um estudo ainda não realizado com dados de fala infantil, mas que já tivesse uma boa descrição e análise da fala vernacular do adulto. A variável dependente escolhida foi a não concordância verbal ou, como trazem Scherre e Naro (1998), a variante zero de concordância. Traremos o estudo desses autores, que ricamente descrevem o fenômeno da concordância variável de número em elementos verbais na fala adulta do PB e, em seguida, nosso estudo com o mesmo fenômeno, sob o prisma da aquisição da linguagem.

\section{A concordância verbal no português falado no Brasil: um estudo de Scherre e Naro}

Scherre e Naro (1998) desenvolveram um estudo, mostrando que o português vernacular do Brasil apresenta variação sistemática nos processos de concordância de número, a qual se configura como um caso de variação inerente e tem sido, de acordo com os autores, amplamente documentada por estudiosos diversos. Este fenômeno apresenta variantes explícitas e variantes zero (0) de plural em elementos verbais e nominais. Como nosso objetivo é estabelecer uma comparação com o estudo que realizamos sobre a mesma variação na fala de crianças, abordaremos aqui apenas os aspectos relevantes para essa comparação. Os exemplos dados pelos autores (SCHERRE; NARO, 1998) estão ilustrados abaixo.

(1) Concordância verbo/sujeito

...eles GANHAM demais da conta (variante explícita); ...eles GANHA0 demais (variante zero). 
O objetivo do estudo de Scherre e Naro (1998) consiste em mostrar claramente que os processos de concordância exibem um sistema perfeito, correlacionado a variáveis linguísticas e sociais, sendo que as variáveis linguísticas consideradas importantes para o entendimento desta variação são: saliência fônica e posição; enquanto as variáveis sociais são: escolarização, faixa etária e sexo. A pesquisa contou com dados do corpus Censo, do Programa de Estudos sobre o Uso da Língua (PEUL), da UFRJ, e, com relação ao aspecto que estamos abordando - a concordância verbal -, a análise envolveu um total de 4.632 construções.

Para o tratamento estatístico dos dados, os autores afirmam ter utilizado um conjunto de programas computacionais apropriado, que fornecem pesos relativos associados aos diversos grupos de variáveis independentes consideradas. A seleção dos grupos, realizada pelo conjunto de programas, demonstra sua relevância para a variação do fenômeno analisado. Os pesos relativos apontam para o efeito de cada um dos fatores sobre as variantes. Essa mesma metodologia nos permitirá realizar a comparação com dados de crianças. A variável dependente no estudo de Scherre e Naro é a variante explícita de plural, diferentemente da nossa pesquisa, que optou por eleger a variante zero como variável dependente.

\section{Análise dos dados}

\section{Análise da variável saliência fônica}

Estudos anteriores a esse de Scherre e Naro (1998) mostraram que um dos fatores que aumenta as chances de concordância verbal é o aumento da saliência do material fônico na oposição singular/plural dos verbos que foram analisados. Naro (1981, p.73-78) estabeleceu dois critérios, a partir dos quais pode ser estabelecida uma hierarquia da saliência: "(1) presença ou ausência de acento na desinência e (2) quantidade de material fônico que diferencia a forma singular da forma do plural". Os níveis da escala de saliência foram elaborados a partir desses critérios, conforme o Quadro 2. O nível 1, conforme Naro (1981, p.74), corresponde à oposição não acentuada e "[...] contém os pares nos quais os segmentos fonéticos que estabelecem a oposição são NÃO-ACENTUADOS em ambos os membros." O nível 2, por sua vez, correspondente à oposição acentuada, "contém aqueles pares nos quais [os segmentos fonéticos que estabelecem a oposição] são ACENTUADOS em pelo menos um membro da oposição." 
Quadro 2 - Quadro formulado a partir de informações obtidas em Scherre e Naro (1998).

\begin{tabular}{|c|c|c|}
\hline \multicolumn{3}{|c|}{ Nível 1 - Oposição não acentuada } \\
\hline a) & $\begin{array}{l}\text { Não envolve mudança na qualidade da } \\
\text { vogal na forma plural }\end{array}$ & $\begin{array}{l}\text { - Eles conhece0 Roma. Conhece Paris } \\
\text { (MOR45MC51/2470) } \\
\text { - Ceys conheceM? (NAD36FG57/1119)6 }\end{array}$ \\
\hline b) & $\begin{array}{l}\text { Envolve mudança na qualidade da vogal } \\
\text { na forma plural }\end{array}$ & $\begin{array}{l}\text { - Eles ganha0 demais po que eles fayz } \\
\text { (CAB02MP16/ 0026) } \\
\text { - Eles ganhaM demais da conta } \\
\text { (CAB02MP16/0012) }\end{array}$ \\
\hline c) & $\begin{array}{l}\text { Envolve acréscimo de segmentos na } \\
\text { forma plural }\end{array}$ & $\begin{array}{l}\text { - Eles também não diz0 } \\
\text { (LAU28FC43/2601) } \\
\text { - Eles dizEM: "chutei tudo" } \\
\text { (HEL34FG62/1887) }\end{array}$ \\
\hline \multicolumn{3}{|c|}{ Nível 2 - Oposição acentuada } \\
\hline a) & $\begin{array}{l}\text { Envolve apenas mudança na qualidade da } \\
\text { vogal na forma plural }\end{array}$ & $\begin{array}{l}\text { - Os filho tá0 pedindo dinhero } \\
\text { (LEI04FP25/0055) } \\
\text { - Eles t tão bem intencionados } \\
\text { (JOS35FP59/0962) }\end{array}$ \\
\hline b) & $\begin{array}{l}\text { Envolve acréscimo de segmentos sem } \\
\text { mudanças vocálicas na forma plural }\end{array}$ & $\begin{array}{l}\text { - Aí bateu0 dois senhores na porta } \\
\text { (NIL12FP45/0646) } \\
\text { - (eles) bateRU sete chapa da cabeça } \\
\text { dele (LEI04FP25/0084) }\end{array}$ \\
\hline & $\begin{array}{l}\text { Envolve acréscimo de segmentos e } \\
\text { mudanças diversas na forma plural: } \\
\text { mudanças vocálicas na desinência, } \\
\text { mudanças na raiz, e até mudanças } \\
\text { completas }\end{array}$ & $\begin{array}{l}\text { - Aí, veio0 aqueles cara correno atrás de } \\
\text { (ALE55MG13/0555) } \\
\text { - vIERAM os ladrões, quatro, hum? } \\
\text { (ARI30FG43/1665) } \\
\text { - Agora, os vizinho daqui é0 ótimo } \\
\text { (EDP13MP62/0758) } \\
\text { - Mesmo aqueles que SÃo sinceros } \\
\text { (EDB07MP41/0334) }\end{array}$ \\
\hline
\end{tabular}

Fonte: Adaptado de Scherre e Naro (1998).

\footnotetext{
6 Todos esses exemplos foram extraídos de Scherre e Naro (1998).

7 Inclui o par foi/foram, que perde a semivogal.
} 
Tomando a tabela apresentada pelos autores, com seus resultados comparados ao estudo de Naro (1981), observamos que os pesos relativos são semelhantes.

Tabela 1 - Variável Saliência Fônica no estudo de Scherre e Naro (1998)

Marcas explícitas de plural nos verbos em função da variável saliência fônica na oposição singular/plural

\begin{tabular}{lcccc}
\hline & \multicolumn{2}{c}{ Resultados Scherre e Naro (1998) } & \multicolumn{2}{c}{ Naro (1981) } \\
\hline Fatores & Frequência & Pesos & Frequência & Peso \\
Nível 1 & & & & \\
\hline 1a & $202 / 463=44 \%$ & 0,16 & $110 / 755=15 \%$ & 0,11 \\
\hline 1b & $1159 / 1766=66 \%$ & 0,37 & $763 / 2540=30 \%$ & 0,26 \\
\hline 1c & $188 / 267=70 \%$ & 0,38 & $99 / 273=36 \%$ & 0,35 \\
\hline Nível 2 & & & & 0,68 \\
\hline 2a & $585 / 718=81 \%$ & 0,64 & $604 / 927=65 \%$ & 0,78 \\
\hline 2b & $212 / 260=82 \%$ & 0,66 & $266 / 365=73 \%$ & 0,85 \\
\hline 2c & $1023 / 1158=88 \%$ & 0,75 & $1160 / 1450=80 \%$ & \\
\hline Total & $3369 / 4632=73 \%$ & & $3002 / 6310=48 \%$ & \\
\hline
\end{tabular}

Fonte: Adaptado de Scherre e Naro (1998).

A Tabela 1 nos mostra que, nos dois estudos relatados, os níveis mais baixos da hierarquia de saliência fônica favorecem menos a concordância do que os níveis mais altos. Em outras palavras, a oposição não acentuada favorece pouco a concordância, e a oposição acentuada favorece mais.

\section{Análise da variável posição}

Conforme Scherre e Naro (1998), diversos estudos têm mostrado que a presença do sujeito e sua posição relativa ao verbo têm forte influência sobre o tipo de variante nas formas verbais. A Tabela 2 nos mostra os diferentes fatores e sua influência no favorecimento das variantes para todos os falantes analisados ${ }^{8}$.

8 No referido estudo, os autores trazem, também, o resultado dividido em faixas de escolarização. 
Tabela 2 - Variável posição do sujeito no estudo de Scherre e Naro (1998).

\begin{tabular}{l|cc}
\hline Fatores & Frequência & Peso relativo \\
\hline Sujeito imediatamente anteposto ao verbo & $1529 / 1857=82 \%$ & 0,62 \\
$\begin{array}{l}\text { Sujeito anteposto separado do verbo por } \mathbf{1} \text { a } \\
\mathbf{4} \text { sílabas }\end{array}$ & $756 / 1025=74 \%$ & 0,65 \\
$\begin{array}{l}\text { Sujeito anteposto separado do verbo por } \mathbf{5} \text { ou } \\
\text { mais sílabas }\end{array}$ & $83 / 135=61 \%$ & 0,39 \\
Sujeito posposto ao verbo & $50 / 194=26 \%$ & 0,08 \\
Sujeito oculto próximo & $731 / 1166=63 \%$ & 0,35 \\
Sujeito oculto distante & $220 / 255=86 \%$ & 0,63 \\
Total de dados & $3369 / 4632=73 \%$ & \\
\hline
\end{tabular}

Fonte: Adaptado de Scherre e Naro (1998).

Esta tabela revela que a posição anteposta do sujeito ou imediatamente mais próxima ao verbo favorece a variante explícita, com pesos relativos de 0,62 e de 0,65 .

Com relação às variáveis sociais, os autores apontam que as mais significativas foram escolarização e sexo.

Na próxima seção, verificaremos como essa variação se dá na fala da criança e avaliaremos, a partir dos resultados, se essa regra variável já foi adquirida por crianças nas faixas etárias que analisamos, 9:1 e 5:9.

\section{A concordância verbal como aquisição de regra variável pela criança}

Como vimos, um estudo variacionista debruçado sobre a fala da criança exige algumas características especiais, que serão detalhadas neste trabalho. Salientamos o fato de que os resultados aqui apresentados consistem em uma pequena exploração desse tipo de estudo, para fins de ilustração. Para uma descrição consistente da aquisição da regra variável de concordância verbal, um estudo mais amplo e detalhado, com mais informantes, seria o ideal.

A variável dependente desta pesquisa, tal como explicitado anteriormente, é a não concordância verbal, diferentemente do estudo de Scherre e Naro. Portanto, a comparação entre os dados exigirá do leitor um pouco mais de atenção. Escolhemos a variante zero como variável dependente, pois era deste ponto de vista que gostaríamos de ver a influência das variáveis independentes. Em outras 
palavras, nossa intenção era observar de que forma as variáveis linguísticas e sociais influenciariam o comportamento desta variante e com que peso.

As variáveis linguísticas independentes selecionadas para este estudo, listadas em (2), fundamentam-se, em parte, no estudo de Scherre e Naro (1998), e, também, em outros estudos sobre a aquisição da variação, já explorados neste trabalho.

(2) Variáveis linguísticas independentes

- Estrutura sintática/prosódica da sentença: declarativa ou interrogativa;

- Posição relativa do sujeito: anteposto ou posposto;

- Contiguidade sujeito-verbo: contíguo, não contíguo, recuperado ou oculto;

- Classe gramatical do sujeito: nome, pronome ou outra;

- Saliência do material fônico na oposição singular/plural (conforme Quadro 1, da seção anterior).

As variáveis sociais foram as listadas em (3).

(3) Variáveis extralinguísticas independentes

- Idade e sexo ${ }^{9}$

- Contexto de produção: brincadeira livre, instrução, formal, leitura de livro (contar histórias)

Na seção seguinte, trataremos da metodologia aplicada a este estudo.

\section{Metodologia}

Aliando conhecimentos das duas áreas que dividem a interface de nosso estudo - a sociolinguística variacionista e a aquisição da linguagem -, elaboramos instrumentos de coleta para a obtenção de dados das crianças e submetemos esses dados a uma análise estatística por meio do pacote de programas GOLDVARB, o qual vem sendo muito utilizado em estudos variacionistas.

\section{Coleta de dados}

Uma coleta de dados com crianças, que tenha por objetivo uma pesquisa de cunho variacionista, exige características especiais: primeiramente porque não se podem eliciar dados de crianças com o mesmo tipo de entrevista que se faz a um adulto; isso porque a criança, em geral, produz um volume menor de dados

9 Aglutinadas em função de que foram apenas dois informantes: uma menina de 9;1 e um menino de 5;9. 
espontâneos em um período de tempo comparado ao da coleta com adultos (normalmente, uma hora); e também porque é preciso pensar em estratégias que contemplem todas as possibilidades de contexto, de variáveis independentes linguísticas e extralinguísticas.

Para a coleta da pesquisa que será aqui relatada, a entrevistadora elaborou técnicas de coleta voltadas especialmente para os informantes em questão, já que eram seus conhecidos e, portanto, algumas atividades foram escolhidas tendo em vista o gosto e as preferências dos informantes. Também foram pensadas atividades que abarcassem momentos de brincadeira (em que se esperava uma fala mais espontânea e despreocupada), de instrução explícita, de leitura de livros (contar de histórias) e de identificação de figuras (em que se esperava uma fala mais formal), inspiradas nos estudos aqui relatados e na afirmação de Labov (2001) de que as variantes formais são associadas à instrução e à punição, enquanto a fala informal é associada à intimidade e à diversão.

Os informantes são duas crianças de 9;1 e de 5;9, respectivamente do sexo feminino e do sexo masculino, de classe média alta, residentes na cidade de São Leopoldo, no estado do Rio Grande do Sul. As crianças moram com seus pais e com seus avós. Os pais têm ensino superior completo; os avós, instrução primária incompleta.

A coleta foi toda intercalada por diversos momentos: de fala espontânea, descuidada, e de fala mais formal. A primeira atividade foi construir um boneco de farinha e sal. O objetivo dessa brincadeira era propiciar um momento de conversa informal, em que as crianças relatassem o que estavam fazendo, como seria o nome de seus "ETs", o que eles faziam, em que mundo moravam, quem eram seus pais, entre outras questões, voltadas à obtenção de contextos de concordância verbal. Essa atividade tomou a maior parte do tempo da entrevista.

Em seguida, enquanto os bonecos estavam no forno, a entrevistadora sugeriu que as crianças contassem a história de seu livro preferido. Esse momento propiciou uma fala um pouco mais formal. A próxima atividade foi um jogo, conhecido como "Pula Macaco", em que, novamente, pôde-se observar uma fala espontânea e despreocupada, intercalada por alguns momentos de instrução explícita, solicitados pela entrevistadora, tais como: "Diga para seus macacos acertarem a árvore!", "Diga para meus macacos me obedecerem!", "Diga aos macacos como devem fazer!". Após o jogo, a entrevistadora sugeriu que as crianças lhe mostrassem um álbum de fotos da viagem que mais gostaram de fazer. O relato das fotografias também previa um fala espontânea, já que, nesse momento, os informantes se concentraram mais na emoção da imagem do que em sua fala. A essa atividade, sucedeu-se mais uma etapa da construção do boneco, também de fala espontânea, em que a entrevistadora conversou com os informantes, fazendo-lhes perguntas que propiciassem a produção da variável em 
questão e, em seguida, uma atividade de descrição de figuras, todas conhecidas pelos informantes, para a obtenção de uma fala mais formal. A última tarefa, também visando a uma fala espontânea, foi a de desenho, em que as crianças desenharam o universo em que moravam seus ETs. Durante a produção do desenho, a entrevistadora solicitou diferentes tipos de fala, mais formal e mais espontânea, por meio de perguntas como: "O que são esses prédios?" " Para que tu desenhou essas janelas?" "Como os pais falam com seus filhos?", "O que eles diriam se eles fugissem?". Esta coleta de dados foi registrada em um gravador digital, para posterior análise, e teve duração de três horas. O levantamento e a análise dos dados serão explicitados na seção a seguir.

\section{Levantamento e análise dos dados}

Da gravação da coleta foram extraídas as sentenças em que observamos contexto de produção da concordância verbal. Esses dados foram registrados na planilha do GOLDVARB para posterior classificação.

O GOLDVARB é um pacote de programas para análise quantitativa multivariada, que revela ao pesquisador quais são as variáveis mais relevantes na produção do fenômeno estudado e que pesos relativos estão correlacionados a cada um dos valores das variáveis independentes, bem como o nível de significância dos resultados obtidos.

Após o registro das sentenças, foram atribuídos códigos às variáveis, para serem lidas pelo programa. O programa selecionou como estatisticamente significantes as variáveis linguísticas posição relativa do sujeito, classe gramatical do sujeito e saliência do material fônico na oposição singular/plural. Nenhuma variável extralinguística foi selecionada pelo programa. As tabelas abaixo mostram os pesos relativos de cada fator.

Tabela 3 - Variável posição relativa do sujeito na fala infantil

Fator Aplicação total Porcentagem Peso relativo

\begin{tabular}{lccc} 
anteposto (eles come) & $25 / 149$ & 90,9 & 0,43 \\
posposto (vai sujar minhas calça) & $9 / 15$ & 9,1 & 0,94 \\
\hline Total & $\mathbf{3 4 / 1 6 4}$ & $\mathbf{2 0 , 7}$ &
\end{tabular}

Input: 0,156

Significância: 0,014

FONTE: GOLDVARB 
A Tabela 3 mostra o resultado da análise multivariada, referente à relação entre a não concordância em verbos e a posição relativa do sujeito, que foi um dos fatores selecionados pelo pacote de análise estatística GOLDVARB, em que o sujeito à direita do verbo apresenta um peso relativo de 0,94, favorecedor do fenômeno da não concordância. O sujeito à esquerda apresenta peso relativo de 0,43, que é menos favorecedor. Em comparação com o estudo de Scherre e Naro (1998), constatamos que o resultado é semelhante. Os autores mostram que o sujeito anteposto favorece a concordância, com peso relativo de 0,62. Em nosso estudo, o sujeito anteposto favorece menos a não concordância, com peso relativo de 0,43 . O sujeito posposto favorece a não concordância, com peso relativo de 0,94. Scherre e Naro verificaram um peso relativo de 0,08 para a influência desse tipo de sujeito sobre a concordância. Embora nossos dados sejam poucos, e a maioria deles tenha se concentrado em sentenças de sujeito anteposto, o que poderia enviesar a amostra, os resultados são semelhantes aos dos adultos. Vejamos os resultados para a classe gramatical do sujeito na Tabela 4.

Tabela 4 - Variável classe gramatical do sujeito na fala infantil

Fator Aplicação total Porcentagem Peso relativo

\begin{tabular}{|c|c|c|c|}
\hline pronome (eles come) & $11 / 87$ & 53,0 & 0,39 \\
\hline $\begin{array}{l}\text { nome (aliens é monstro que não } \\
\text { são humanos) }\end{array}$ & $21 / 64$ & 39,0 & 0,68 \\
\hline outros (é duas que eu não faço) & $2 / 13$ & 7,9 & 0,27 \\
\hline Total & $34 / 164$ & 20,7 & \\
\hline
\end{tabular}

Input: 0,156

Significância: 0,014

FONTE: GOLDVARB

A Tabela 4 mostra os resultados referentes ao fator classe gramatical do sujeito. Os sujeitos constituídos por nomes apresentam-se favorecedores à aplicação da não concordância em verbos, com um peso relativo de 0,68. Os demais sujeitos, pronominais e outros, apresentam pesos que favorecem menos a aplicação: 0,39 e 0,27 respectivamente. Essa variável não consta no estudo de Scherre e Naro, impossibilitando a comparação, mas apresenta-se como relevante em um estudo como este. A escolha desta variável foi inspirada no estudo de Smith, Durham e Fortune (2007) sobre a marcação de plural no inglês. Passemos à tabela da última variável selecionada. 
Tabela 5 - Variável saliência fônica na fala infantil

$\begin{array}{lccc}\begin{array}{l}\text { OpNA } \\ \text { na forma plural (eles faz/fazem) }\end{array} & 4 / 10 & 40,0 & 0,83 \\ \begin{array}{l}\text { OpNA - não envolve mudança na } \\ \text { qualidade da vogal na forma plural } \\ \text { (eles come/comem) }\end{array} & 9 / 24 & 37,5 & 0,82\end{array}$

OpA - acréscimo de segmentos e mudanças diversas na qualidade da forma plural (aliens é/são monstro $110 / 58$ 17,5 0,40 que não são humanos)

OpNA - mudança na qualidade da vogal na forma plural ((e os meninos) $7 / 44$ 15,9 0,43 só pensa/pensam em comer)

OpA - mudança apenas na qualidade da vogal na forma plural ((os olhos) ta/tão aqui ó)

$\begin{array}{lll}4 / 28 & 14,3 & 0,32\end{array}$

Total

$34 / 164$

20,7

Input: 0,156

Significância: 0,014

FONTE: GOLDVARB

Com relação à saliência do material fônico, dois fatores apresentam pesos relativos que indicam o favorecimento da aplicação da regra variável de não concordância do plural em verbos: o acréscimo de segmentos na forma plural e a mudança na qualidade da vogal na forma plural, ambos em oposição singular/ plural não acentuada. As demais formas apresentam pesos relativos menos favorecedores à aplicação. Esse resultado também está de acordo com o estudo referente à fala adulta, já que, como afirmam Scherre e Naro (1998), a oposição acentuada favorece a concordância, e a oposição não acentuada favorece a não concordância. Em outras palavras, quanto maior for a saliência fônica, maior a tendência à aplicação da concordância. Nesta tabela, vemos que a oposição não acentuada, em dois de seus critérios, favoreceu a não concordância, com pesos relativos de 0,82 e 0,83.

Os resultados que obtivemos com a análise da não concordância verbal apresentam apenas tendências que devem ser investigadas em uma pesquisa

10 OpNA= Oposição não acentuada; OpA = Oposição acentuada (SCHERRE; NARO, 1998). 
com mais sujeitos e mais dados. Como já comentamos, este estudo tem apenas a intenção de ser um exercício de pesquisa variacionista com um olhar para dados de fala infantil, com o objetivo de propor uma ilustração para a interface abordada neste estudo. O que podemos verificar é que esses resultados apontam para o fato de que os contextos linguísticos desse tipo de produção estão adquiridos aos 5;9 anos de idade. Os contextos extralinguísticos ou ainda não foram adquiridos ou se faz necessário um ajuste no instrumento de coleta para que outros achados possam emergir. Podemos dizer que a regra parece ter sido adquirida, pelo menos no que se refere à parte linguística, nas idades investigadas. Outra possibilidade interessante de estudo é utilizar dados de crianças mais novas.

Retomando as questões de Roberts (1997), podemos pensar que as crianças adquiriam as restrições internas da regra variável de concordância verbal e que realmente elas estão adquirindo essas regras, e não simplesmente copiando as formas de superfície de seus pais, já que mostram um padrão sistemático e organizado de aquisição. Além disso, evidências de outros dados de fala infantil nos fornecem pistas de que a variação da concordância é um padrão a ser adquirido, já que, em uma das etapas de aquisição da morfologia verbal e nominal, as crianças lidam com a regra de plural de diferentes formas, indicando ser uma regra a ser adquirida, tal como ilustrado nos exemplos em (4).

(4) Dados de crianças sobre o plural ${ }^{11}$

a) O galhos é duro $(0 ., 2 ; 1)$

a) Os patos voas (B., 1;9)

Roberts (1997) ainda questiona se as regras podem ser construídas como um reflexo de processos naturais, universais, que afetam a aquisição da linguagem, mas essa resposta exige um trabalho de pesquisa e estudo mais aprofundado e detalhado.

\section{Conclusão}

A aquisição da variação é uma área ainda pouquíssimo explorada no Brasil e que merece atenção, pois tem mostrado resultados importantes tanto para a área de aquisição da linguagem quanto para a de variação linguística, situando a criança como membro da comunidade de fala e, portanto, como informante de pesquisas que visam a uma abordagem completa da comunidade e de seu dialeto e como membro ativo nos processos de manutenção e de mudança do vernáculo. Além disso, salientam sua relevância para os estudos em aquisição da linguagem,

11 Dados coletados para minha tese de doutorado (LORANDI, 2011). 
pois revelam aspectos do processo de aquisição ainda pouco investigados, dada a tradição de se estudarem, no processo de aquisição, apenas aspectos de homogeneidade e de regularidade referentes ao padrão.

Para este trabalho, trouxemos alguns estudos importantes desenvolvidos no âmbito da aquisição da variação, com o objetivo de ilustrar o que tem sido feito nessa área e também apresentamos um exercício de análise sociovariacionista de dados de aquisição da linguagem, com o propósito de ilustrar uma coleta de dados que objetivou a aquisição da regra variável de concordância verbal. Os resultados encontrados, embora ilustrativos, apontam para o fato de que crianças de 5;9 já adquiriram regras internas à variação, tal como os adultos. Para fins de comparação, utilizamos os estudos de Scherre e Naro (1998) sobre a variação da concordância verbal em adultos.

Olhar para dados da criança, além de trazer informações importantes para a participação desta enquanto falante de uma comunidade linguística, contribui para os estudos de aquisição da linguagem, que têm por objetivo descrever, acompanhar e explicar o desenvolvimento da linguagem da criança. Averiguar o momento em que determinada regra variável é adquirida pela criança é, portanto, uma investigação valiosa para estudiosos de ambas as áreas desta interface.

LORANDI, A. Variation acquisition: interface between language acquisition and language variation. Alfa, São Paulo, v.57, n.1, p.133-162, 2013.

- ABSTRACT: This work consists of an explanation of a rather valuable field of study that arises from an interface between language acquisition and variationist sociolinguistics - variation acquisition. From important studies conducted in this field, we approach concepts that are fundamental to the understanding of variation acquisition and children as members of the linguistic community. The aim of this work is to present a theoretical framework on variation acquisition studies, because this is a still poorly explored phenomenon in the Brazilian academic world. This work also presents a variationist research exercise, with child speech data on the verbal agreement variable phenomena (based on Scherre and Naro, 1998). For this purpose, we developed a data collection strategy, as proposed by variationist sociolinguistics, with some adaptations to children's work, as suggested by important studies, like those from Roberts (1997, 2002, 2005).

- KEYWORDS: Variation acquisition. Sociolinguistics. Verbal agreement.

\section{REFERÊNCIAS}

ANDERSEN, E. Speaking with style: the sociolinguistic skills of children. New York: Routledge, 1990.

BAILEY, G. Real and apparent time. In: CHAMBERS, J. K. et al. The Handbook of language variation and change. Malden: Blackweel, 2004. p.312-332. 
CHAMBERS, J. K. Sociolinguistic theory. Oxford: Blackwell, 2003.

FEAGIN, C. Entering the community: fieldwork. In: CHAMBERS, J. K.; SCHILLINGESTES, N.; TRUDGILL, P. (Ed.). Handbook of language variation \& change. Oxford: Blackwell, 2002. p.20-39.

FISCHER, J. Social influence in the choice of a linguistic variant. Word, New York, v.14, p.47-56, 1958.

FOULKES, P.; DOCHERTY, G. The social life of phonetics and phonology. Journal of Phonetics, London, v.34, p.409-438, 2006.

FOULKES, P.; DOCHERTY, G.; WATT, D. Phonological variation in child-directed speech. Language, Baltimore, v.81, p.77-206, 2005.

Tracking the emergence of structured variation: realizations of (t) by Newcastle children. Leeds working papers in linguistics and phonetics, Leeds, v.7, p.1-25, 1999.

GUY, G. Variation in the group and the individual: the case of final stop deletion. In: LABOV, W. (Ed.). Locating language in time and space. New York: Academic Press, 1980. p.1-36.

GUY, G.; BOYD, S. The development of a morphological class. Language Variation and Change, Cambridge, v.2, p.1-18, 1990.

GUY, G.; ZILLES, A. Sociolingüística quantitativa: instrumental de análise. São Paulo: Parábola, 2007.

KERSWILL, P. Children, adolescents and language change. Language Variation and Change, Cambridge, v.8, p.177-202, 1996.

KOVAC, C.; ADAMSON, H. D. Variation theory and first language acquisition. In: SANKOFF, D.; CEDERGREN, H. (Ed.). Variation omnibus. Edmonton: Linguistic Research, 1981. p.403-410.

LABOV, W. Principles of linguistic change. Oxford: Blackwell, 2001. v. 2.

. Principles of linguistic change. Oxford: Blackwell, 1994. v.1.

The child as linguistic historian. Language Variation and Change, Cambridge, v.1, p.85-98, 1989.

Contraction, deletion and inherent variability of the English copula. Language, Baltimore, v.45, p.715-762, 1969.

Stages in the acquisition of standard english. In: SHUY, R. (Ed.). Social dialects and language learning. Champaign: National Council of Teachers of English, 1964. p.77-103. 
LORANDI, A. From sensitivity to awareness: the morphological knowledge of Brazilian children between 2 and 11 years old and the representational redescription model. 2011. 201f. Tese (Doutorado em Letras) - Faculdade de Letras, Pontifícia Universidade Católica do Rio Grande do Sul, Porto Alegre, 2011.

NARO,A. J. The social and structural dimensions of a syntactic change. Language, Baltimore, v.57, n.1, p.63-98, 1981.

NARO. A. J.; SCHERRE, M. Origens do português brasileiro. São Paulo: Parábola, 2007.

NEWPORT, E. L. Motherese: the speech of mothers to young children. In: CASTELLAN, N. J.; PISONI, D. B.; POTTS, G. R. (Ed.). Cognitive theory. Hillsdale: Lawrence Erlbaum Associates, 1977. v.2. p.177-217.

PURCELL, A. Code shifting Hawaiian style: children's accommodation along a decreolizing continuum. International Journal of the Sociology of Language, Berlin, v.46, p.71-86, 1984.

ROBERTS, J. Acquisition of sociolinguistic variation. In: BALL, M. J. (Ed.). Clinical Sociolinguistics. Oxford: Blackwell, 2005. p.153-164.

Child language variation. In: CHAMBERS, J.; SCHILLING-ESTES, N.; TRUDGILL, P. (Ed.). Handbook of language variation \& change. Oxford: Blackwell, 2002.

. Acquisition of variable rules: a study of $(t, d)$ deletion in preschool childrem. J. Child Language, Cambridge, v.24, p.351-372, 1997.

ROBERTS, J.; LABOV, W. Learning to talk Philadelfian: acquisition of short a by preschool children. Language Variation and Change, Cambridge, v.7, p.101-112, 1995.

SCHERRE, M. M. P.; NARO, A. J. Sobre a concordância de número no português falado do Brasil. In: RUFFINO, G. (Org.). Dialettologia, geolinguistica, sociolinguistica. (Atti del XXI Congresso Internazionale di Linguistica e Filologia Romanza) Centro di Studi Filologici e Linguistici Siciliani, Universitá di Palermo. Tubingen: Max Niemeyer Verlag, 1998. v.5. p.509-523.

SMITH, J.; DURHAM, M.; FORTUNE, L. "Mam, my trousers is fa'in doon!": community, caregiver, and child in the acquisition of variation in a Scottish dialect. Language Variation and Change, Cambridge, v.19, p.63-99, 2007.

SNOW, C. E. Mothers' speech to children learning language. Child Development, Chicago, v.43, p.549-565, 1972.

TARALLO, F. A pesquisa sociolinguística. São Paulo: Ática, 2002. 
WEINREICH, U.; LABOV, W.; HERZOG, M. Empirical foundations for a theory of language. In: LEHMAN,W.; MALKIEL, Y. (Ed.). Directions for Historical Linguistics. Austin: University of Texas Press, 1968. p.95-188.

WEXLER, K.; CULICOVER, P. Formal principles of language acquisition. Cambridge: MIT Press, 1980.

Recebido em 19 de setembro de 2011

Aprovado em 24 de novembro de 2012 